\title{
Coordinated radar observations of atmospheric diurnal tides in equatorial regions
}

\author{
Toshitaka Tsuda ${ }^{1}$, Kazunori Ohnishi ${ }^{1}$, Fusako Isoda ${ }^{1}$, Takuji Nakamura ${ }^{1}$, Robert A. Vincent ${ }^{2}$, Iain M. Reid ${ }^{2}$, \\ Sri Woro B. Harijono ${ }^{3}$, Tien Sribimawati ${ }^{3}$, Agus Nuryanto ${ }^{4}$, and Harsono Wiryosumarto ${ }^{4}$ \\ ${ }^{1}$ Radio Atmospheric Science Center (RASC), Kyoto University, Uji, Kyoto 611-0011, Japan \\ ${ }^{2}$ Department of Physics and Mathematics, University of Adelaide, Adelaide 5005, Australia \\ ${ }^{3}$ Agency for the Assessment and Application of Technology (BPPT), Jl. M. H. Thamrin No. 8, Jakarta 10340, Indonesia \\ ${ }^{4}$ Indonesian National Institute of Aeronautics and Space (LAPAN), Jl. Pemuda Persil No. 1, Jakarta Timur 13220, Indonesia
}

(Received August 16, 1998; Revised June 9, 1999; Accepted June 9, 1999)

\begin{abstract}
The long-term behavior of atmospheric tides in the mesosphere and lower thermosphere has been observed with the meteor wind radar (MWR) in Jakarta, Indonesia $\left(6^{\circ} \mathrm{S}, 107^{\circ} \mathrm{E}\right)$ from November 1992 to August 1997. The amplitudes and phases of the diurnal tides show systematic seasonal variations, particularly distinct in the meridional component. In addition, substantial interannual variability is evident, characterized by a biennial periodicity of tidal parameters, and considerably small tidal amplitudes exclusively seen in 1996. The MWR results are compared with the Global Scale Wave Model (GSWM) as well as MF radar data collected in two equatorial sites in Pontianak $\left(0.03^{\circ} \mathrm{N}, 109^{\circ} \mathrm{E}\right)$ and Christmas Island $\left(2^{\circ} \mathrm{N}, 158^{\circ} \mathrm{W}\right)$ for November 1995-July 1997 and January 1996-October 1997, respectively. Comparison studies of these radar data have revealed the detailed latitudinal structure of the diurnal tide near the equator. The GSWM has successfully described the general characteristics of the radar results, although some discrepancies are recognized. In 1996 when radar data are available at all the three sites, the monthly mean values of tidal amplitudes at $90 \mathrm{~km}$ agreed very well between Jakarta and Pontianak, while significant discrepancy was found for Christmas Island, suggesting the existence of geographical effects such as non-migrating tides.
\end{abstract}

\section{Introduction}

The atmospheric tide, one of the most dominant waves in the mesosphere and lower thermosphere (MLT) region, is primarily generated by thermal forcing due to absorption of solar infrared and ultraviolet radiation by water vapor in the troposphere and stratospheric ozone, respectively. Diurnal and semidiurnal tides are normally predominant, although higher harmonics of the 24 hour periodicity of tidal excitation sources are also detected, such as terdiurnal and quarterdiurnal tides.

The amount of atmospheric minor constituents that absorb solar radiation can fundamentally be assumed not to show a significant variation in the longitudinal distribution. Therefore, the corresponding tidal generation also becomes zonally homogeneous, so the tides propagate westward, synchronizing with the apparent motion of the sun. This sun synchronous component is commonly called the migrating tide. The behavior of migrating tides has been studied in a number of theoretical works by employing classical tidal theory (e.g., Kato, 1980), mechanistic models (e.g., Vial, 1986) and general circulation models (e.g., Tokioka and Yagai, 1987). On the basis of the two-dimensional steady model by Forbes (1982) and Forbes and Hagan (1988), Hagan et al. (1995) have developed the Global Scale Wave Model (GSWM), incorporating a more realistic dissipation process, which provides variations of tidal parameters in solstices and

Copy right (C) The Society of Geomagnetism and Earth, Planetary and Space Sciences (SGEPSS); The Seismological Society of Japan; The Volcanological Society of Japan; The Geodetic Society of Japan; The Japanese Society for Planetary Sciences. equinoxes. The GSWM has now been distributed as a reference for a detailed comparison of observed tidal parameters.

In addition to the sun-synchronous tides, non-migrating tides can be generated by a localized excitation source, such as a longitudinal non-uniformity of water vapor content and the cloud convective activity as well as a land-sea contrast in the heat transfer processes within the planetary boundary layer (Hsu and Hoskins, 1989; Williams and Avery, 1996; Ekanayake et al., 1997). Following classical tidal theory, the localized distribution of a heat source can be expanded into a series of positive and negative longitudinal wavenumbers. Therefore, the non-migrating tides consist of various zonal wavenumbers, propagating both westward and eastward, or standing (Tsuda and Kato, 1989).

The propagating wave components of atmospheric tides transport momentum and wave energy upward from the regions of excitation, they then dissipate by various instabilities and wave-wave or wave-mean flow interactions. The tidal amplitudes could become comparable to the mean winds in the MLT region, and the effects of tidal wave breaking must be considered to explain the characteristics of atmosphere dynamics in the MLT region (e.g., Miyahara et al., 1993). According to a classical tidal theory, the propagating diurnal tides are mainly confined in low latitudes $\left(30^{\circ} \mathrm{N}-30^{\circ} \mathrm{S}\right)$. Therefore, the dynamical coupling caused by the breaking of tides can most vigorously be recognized in tropics, although the effects of mean winds on tidal propagation could modify the latitudinal distribution of tides.

Horizontal wind velocity fluctuations caused by atmospheric tides have been extensively observed with a ground- 
based radar, represented by a medium frequency (MF) and a meteor wind radar (MWR), by taking advantages of their capability for long-term measurements (e.g., Tsuda et al., 1988; Vincent et al., 1988; Manson et al., 1989). MF radars can collect wind data with a time resolution of several minutes in a height range of 60-100 km during the day and 70-100 $\mathrm{km}$ at night. Therefore, MF radars are most suitable to determine tidal parameters at $70-100 \mathrm{~km}$ where data are available throughout a day. MWR's have also been widely utilized to measure horizontal wind velocity at $70-100 \mathrm{~km}$ with a time resolution of a few hours. Because data acquisition rate of MWR shows a clear diurnal variation with a maximum and minimum at around 6 and $18 \mathrm{LT}$, respectively, a harmonic fit is required to analyze the tidal behavior that is synchronous to local time.

Hemispheric asymmetry in the atmospheric tides in the MLT region have been studied extensively with radar over the last decades. Simultaneous observations in 1983-95 with the MWR at Kyoto $\left(35^{\circ} \mathrm{N}, 136^{\circ} \mathrm{E}\right)$ and the MF radar in Adelaide $\left(35^{\circ} \mathrm{S}, 138^{\circ} \mathrm{E}\right)$ located at conjugate locations relative to the equator, revealed hemispheric asymmetry in the behavior of both diurnal and semidiurnal tides (Vincent et al., 1988). In particular the amplitudes of diurnal tides were much larger in the southern hemisphere, suggesting a hemispheric difference in the turbulent dissipation. Tidal phases showed a distinct annual variation at both Kyoto and Adelaide, although they were 6 months out of phase.

Because most of coordinated radar studies were carried out at middle and high latitudes, the behavior of tides in the equatorial region has not been fully clarified yet. Over the past decade two new MF radar sites have been established at low latitudes, Christmas Island $\left(2^{\circ} \mathrm{N}, 157^{\circ} \mathrm{W}\right)$ (Vincent and Lesicar, 1991), and Kauai, Hawaii $\left(22^{\circ} \mathrm{N}, 160^{\circ} \mathrm{W}\right)$ (Fritts and Isler, 1992). Comparing these MF radar data with the longterm observations at Adelaide, Vincent et al. (1998) studied the latitudinal structure of diurnal and semidiurnal tides in the equatorial and subtropical regions of Pacific, and reported that the amplitudes and phases of the diurnal tides agreed well with the GSWM, especially at Adelaide and Kauai.

A MWR was installed near Jakarta in November 1992 by a collaboration between Japan and Indonesia, and has been operated continuously for more than five years (Tsuda et al., 1995). MWR observations showed that monthly mean profile of diurnal tides in the MLT region can mostly be described by the migrating components (Tsuda et al., 1997). Combining data-sets collected with the Jakarta MWR and three MF radars at Christmas Island, Kauai and Adelaide, Nakamura et al. (1997) examined the short-period variability of diurnal tides on time scales of 5-30 day, and further discussed importance of the interactions between tides and gravity waves.

By taking advantages of the global coverage of satellite observations, UARS/HRDI has clarified the climatological behavior of atmospheric tides, and reported a reasonable agreement with GSWM (Burrage et al., 1995a, b). Lieberman (1997) analyzed long-term satellite observations from 199295 , and found significant semiannual and interannual variability of the propagating diurnal tide.

GSWM and observational studies have suggested that atmospheric tides in the equatorial region involve large vari- ations as a function of time, height, latitude and longitude, producing a complicated time-height structure. This motivates further investigation of tidal behavior by a coordinated radar network distributed closed to the equator. Through an international collaboration between three research groups in Indonesia, Australia and Japan, a MF radar has been recently installed in Pontianak $\left(0.03^{\circ} \mathrm{N}, 109^{\circ} \mathrm{E}\right)$, Indonesia, and has operated from November 1995 to July 1997. The aim in this paper is to present radar data collected with the Jakarta MWR and MF radars in Pontianak and Christmas Island, and to discuss the the climatological characteristics of diurnal tides in the equatorial region.

\section{Observations and Data Analysis Technique 2.1 MWR in Jakarta}

Since November 1992 we have been continuing MWR observations in an observatory in the Indonesian National Center for Research, Science and Technology (PUSPIPTEK) $\left(6.4^{\circ} \mathrm{S}, 106.7^{\circ} \mathrm{E}\right)$, located about $27 \mathrm{~km}$ south-west of Jakarta (Tsuda et al., 1995). MWR is operated on $31.57 \mathrm{MHz}$ with a peak transmitting power of $10 \mathrm{~kW}$ with a $5 \%$ duty cycle. The MWR utilizes a five element Yagi antenna having a fairly large beam width, and measures the location of meteor echoes with an interferometer system. We first determine the radial wind velocity for individual meteor echoes that distribute widely in azimuth angles. Then, zonal and meridional winds are fitted in a height-time bin of $2 \mathrm{~km}$ and 1 hour, by assuming a uniform and constant wind in the bin. Fitting is not performed when number of meteor echoes in each bin is less than 5. Because the antennas were mostly pointed toward the north at an elevation angle of $45^{\circ}$ during these experiments, the radial winds are relatively more contributed by the meridional component. Therefore, accuracy for the wind velocity estimates can be better for the meridional component than the zonal winds. Note that the effective latitude for the center of MWR observation area is shifted toward north by about half degree.

Total number of meteor echoes per day ranges from 1,000 to 2,000 , giving a mean hourly rate of 40 to 80 . Since we are interested in climatology of the atmospheric tides in the present study, we have accumulated data in a segment with a duration of 31 days and averaged them according to local time. While, short-term variability of tides was reported by Nakamura et al. (1997) from determinations of tidal parameters every 4 days. The local time variation of the eastward and northward wind velocity at each altitude is separately fitted by mean winds, 24 hour and 12 hour oscillations. Finally, we obtain a profile of the amplitudes and maximum phases in local time of both diurnal and semidiurnal tides at 75-105 km. Note that tidal parameters are estimated every day by sliding the 31-day data segment with a time step of one day.

\subsection{MF radars in Pontianak and Christmas Island}

Considering the sharp gradients of tidal amplitudes near the equator, which is also accompanied by the rapid changes in the tidal phases, it has become important to establish a radar observatory very close to the equator. The Indonesian national institute of aeronautics and space (LAPAN) has been operating an ionosonde station in Pontianak, West Kalimantan, and located a new observatory of $3 \times 3 \mathrm{~km}$ 

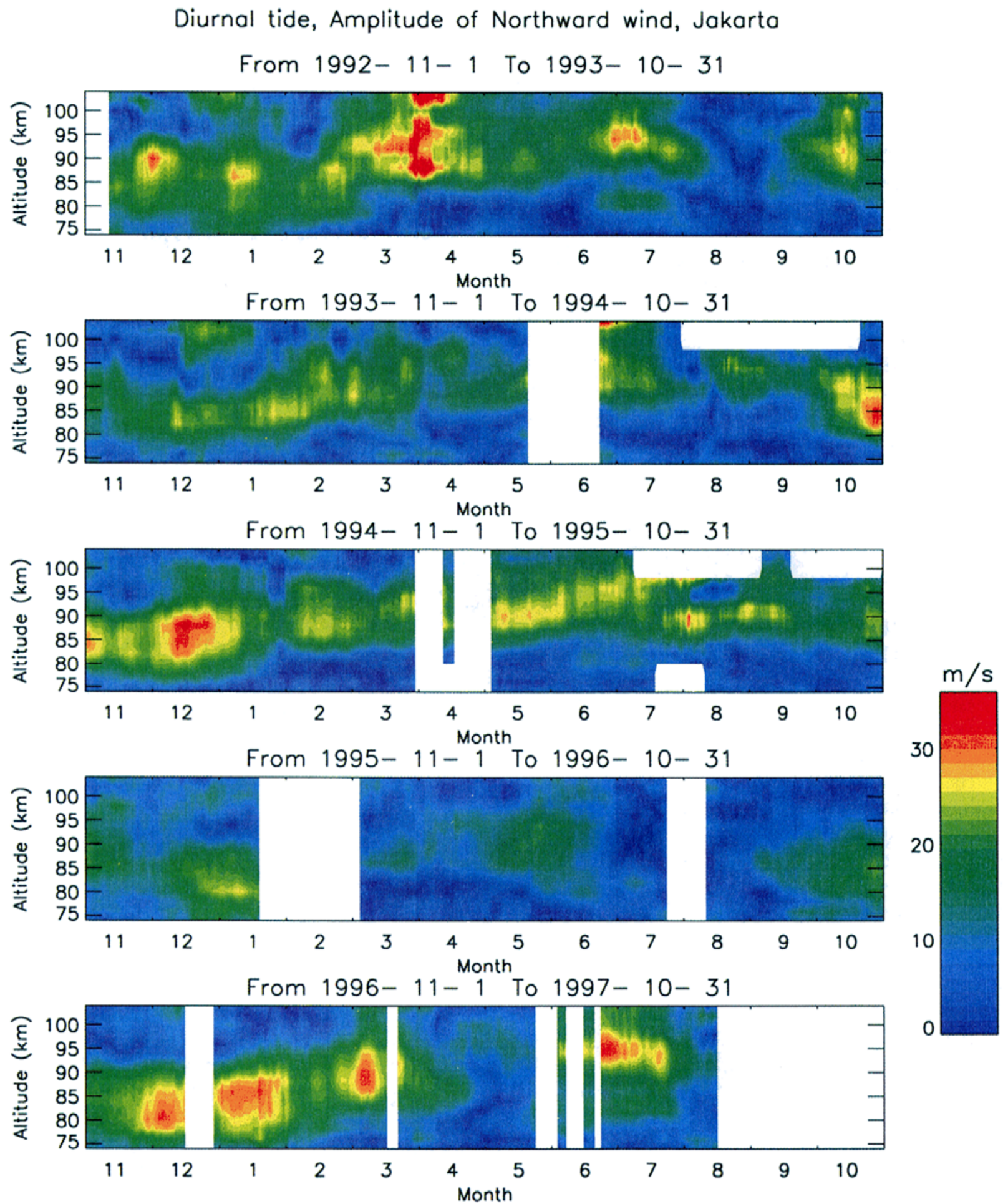

Fig. 1. Time-height cross sections of the amplitudes for the meridional component of the diurnal tide observed from November 1992 to July 1997 at Jakarta

in a tropical forest just outside the city area. In the center of the new site the $300 \times 300 \mathrm{~m}$ is reserved for a construction of the MF radar. The Pontianak MF radar is operated on 1.98 $\mathrm{MHz}$, with a peak transmitting power of $25 \mathrm{~kW}$. A single pulse with a duration of $25 \mu \mathrm{sec}$ is transmitted at a repetition cycle of $80 \mathrm{~Hz}$. The transmitting antenna is a square array of four half-wave dipole antennas raised $20 \mathrm{~m}$ above the ground. Three receiving antennas, each consists of a crossed dipole at $10 \mathrm{~m}$ elevation, are located at an apex of an equilateral triangle with a side length of about $180 \mathrm{~m}$.

The exact coordinates for the center of the antenna array is $0.03^{\circ} \mathrm{N}$ and $109.3^{\circ} \mathrm{E}$ (only $3 \mathrm{~km}$ away from the equator toward north). The Pontianak MF radar interpolates an existing radar network, including Shigaraki (Kyoto), Adelaide, Jakarta and Christmas Island, which is very suitable to investigate the latitudinal structure of atmospheric tides, including 
the hemispheric differences. In particular, the three tropical sites located on $2^{\circ} \mathrm{N}, 6^{\circ} \mathrm{S}$ and the equator provide a valuable data-set for the study of the detailed behavior of atmospheric tides near the equator. Moreover, Jakarta and Pontianak are nearly aligned on the same meridian, while Christmas Island is apart from these along longitude by $94^{\circ}-97^{\circ}$ toward east, so, the effects of local tides can be identified.

We have operated the Pontianak MF radar from November 1995 to July 1997 , and obtained wind velocity profiles at $60-100 \mathrm{~km}$ and $80-100 \mathrm{~km}$ during daytime and at night, respectively. For a tidal analysis we restricted the height range to $80-100 \mathrm{~km}$, where wind velocity data is available throughout a day. The effective height resolution is about $4 \mathrm{~km}$, corresponding to the radar pulse length of $25 \mu \mathrm{sec}$, but, the received echo is sampled every $2 \mathrm{~km}$. Although the time resolution of raw data is 2 minutes, we averaged for one hour in this study. Then, tidal amplitudes and phases are determined by means of a least squares fitting on the time series at each altitude with the segment length of 31 days. Data from the Christmas Island MF radar data is analyzed in the same way from January 1996 to October 1997.

\section{Long-Term Variations of Diurnal Tide at Jakarta}

\subsection{Amplitudes of diurnal tide}

We present in Fig. 1 a time-height contour for the amplitudes of the meridional wind velocity of the diurnal tide, observed with the Jakarta MWR from November 1992 to August 1997. Figure 1 indicates that the tidal amplitudes became maximum at around $80-95 \mathrm{~km}$, and they were smaller above and below. In 1992-1995 the peak amplitudes, exceeding $30 \mathrm{~m} / \mathrm{s}$, were seen in March-April 1993 and from October 1994 to January 1995. The enhanced amplitudes were also recognized from November 1996 to March 1997 and in June-July, 1997. However, from November 1995 to October 1996 the amplitudes in Fig. 1 (second panel from the bottom) were significantly smaller than in other years. Therefore, there existed considerable year-to-year variations.

However, a seasonal cycle of the tidal amplitudes can clearly be recognized in Fig. 1. From November 1994 to October 1995 (third panel in Fig. 1) a yellow region where the tidal amplitudes were larger than $20 \mathrm{~m} / \mathrm{s}$ appeared below about $90 \mathrm{~km}$ in November, and gradually increased to 90-100 km in July, then it descended to 85-90 km in October. The distinct seasonal variation in the peak altitude of the tidal amplitudes was generally recognized in other years. Although the tidal amplitudes were generally small in 1996, a general tendency of the enhanced amplitude region shows a similar seasonal cycle to other years.

Figures 2(a) and (b) show time series of the tidal amplitudes at 82, 88 and $94 \mathrm{~km}$ for the meridional and zonal components, respectively. The results are obtained by applying a low pass filter with a cutoff at 60 days on the daily determinations with a segment of 31 days.

The meridional amplitudes at $82 \mathrm{~km}$ is characterized by a clear annual cycle, showing a large enhancement in November-January. A secondary peak appeared in the middle of a year (May-June) in 1993, 1995, 1996 and 1997 at $82 \mathrm{~km}$, whose amplitudes rapidly increased at 88 and $94 \mathrm{~km}$. As a result, the annual variation appeared at $82 \mathrm{~km}$ is not

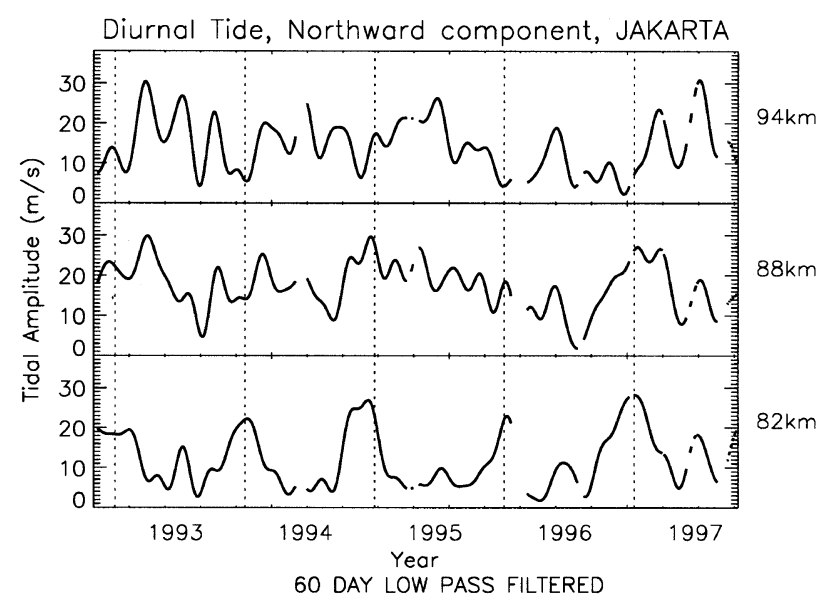

(a)

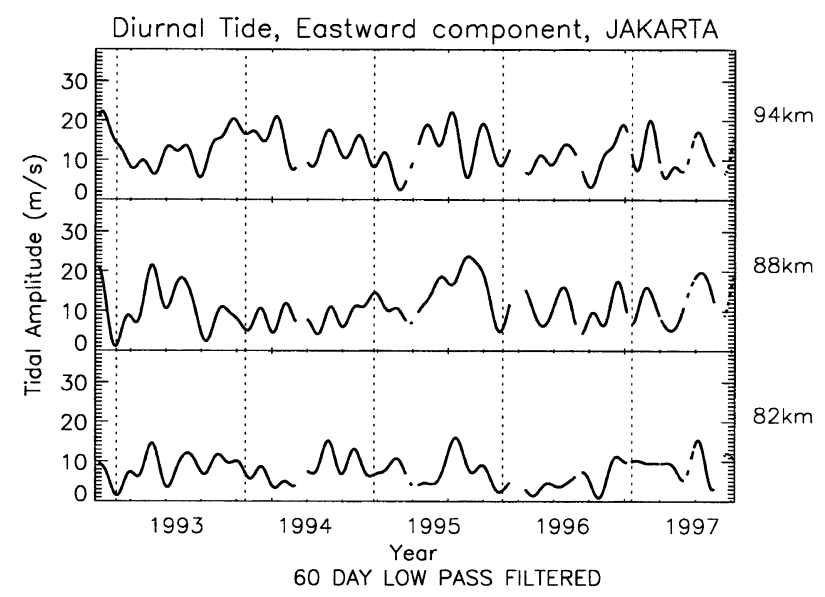

(b)

Fig. 2. Time variations of the amplitudes for (a) meridional and (b) zonal component of the diurnal tide at 82,88 and $94 \mathrm{~km}$ at Jakarta. Results are plotted every day by sliding a 31-day data segment. Then, a low-pass filter with a cutoff at 60 days is applied.

so conspicuous any more at $88 \mathrm{~km}$. Furthermore, at $94 \mathrm{~km}$ the maximum amplitudes are recognized in May-June. It is noteworthy that the amplitudes at $88 \mathrm{~km}$ from November to February were larger in 1992-93, 1994-95 and 1996-97 than in 1993-94 and 1995-96, suggesting a biennial periodicity of the maximum tidal amplitudes. In addition, it is clear that tidal amplitudes were significantly depressed from late 1995 to 1996 , and seem to recover in 1997.

The zonal amplitudes shown in Fig. 2(b) were about 10 $\mathrm{m} / \mathrm{s}$ at $82 \mathrm{~km}$ and increased to $15 \mathrm{~m} / \mathrm{s}$ at 88 and $94 \mathrm{~km}$, which were generally smaller than the meridional component. The maximum zonal amplitudes at 88-94 km were less than 20 $\mathrm{m} / \mathrm{s}$, while the meridional ones sometimes exceeded $30 \mathrm{~m} / \mathrm{s}$. There is not a clear seasonal cycle in Fig. 2(b). However, the zonal amplitudes at $88 \mathrm{~km}$ were considerably enhanced in March-May, 1993 and July-September, 1995, suggesting the variations with a time-scale longer than one year.

\subsection{Maximum phases of diurnal tides}

Figure 3 shows a time-height contour of the tidal phase, which is defined as the local time of the maximum northward 


\section{Diurnal tide, Phase of Northward wind, Jakarta}
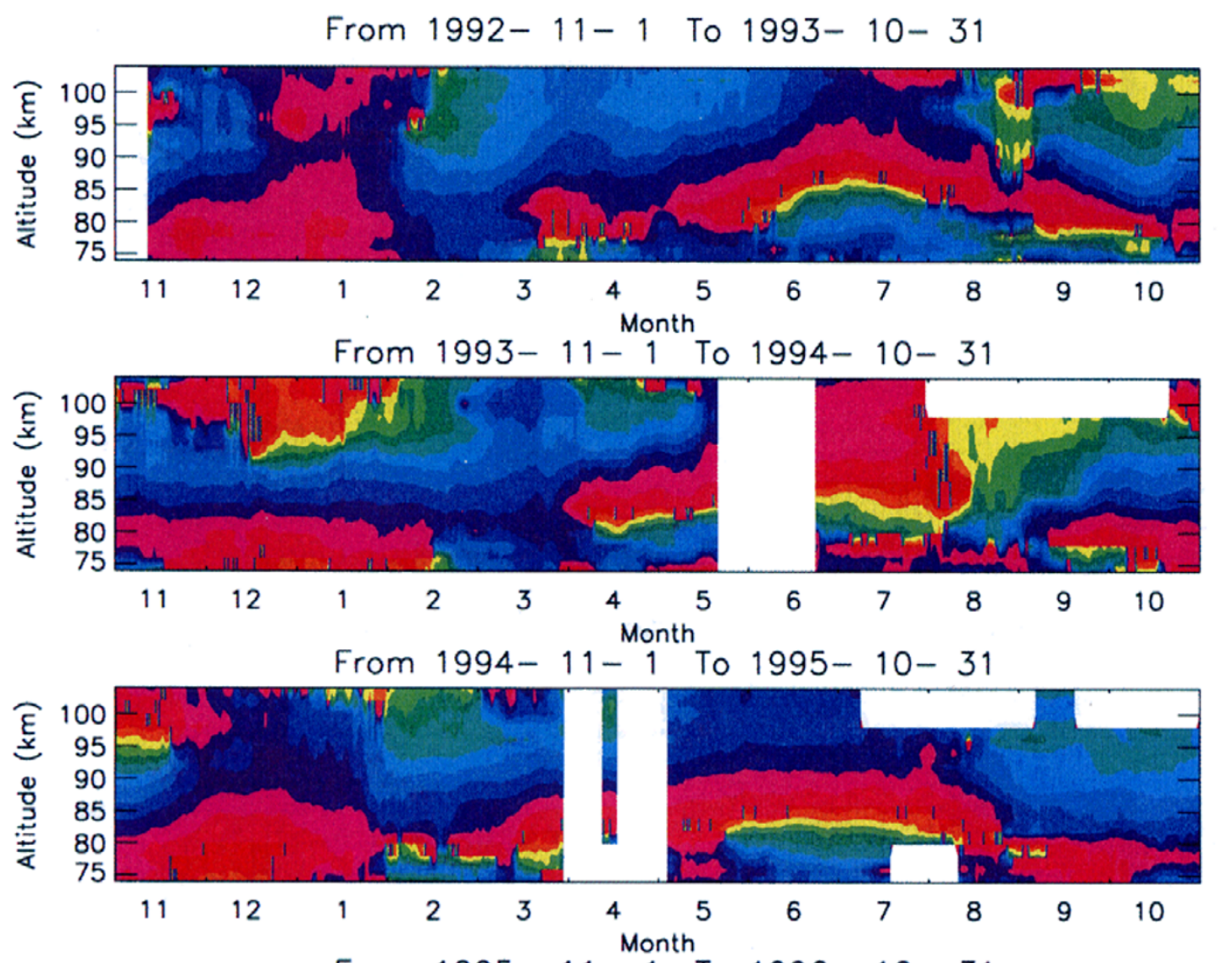

From 1995- 11- 1 To $1996-10-31$

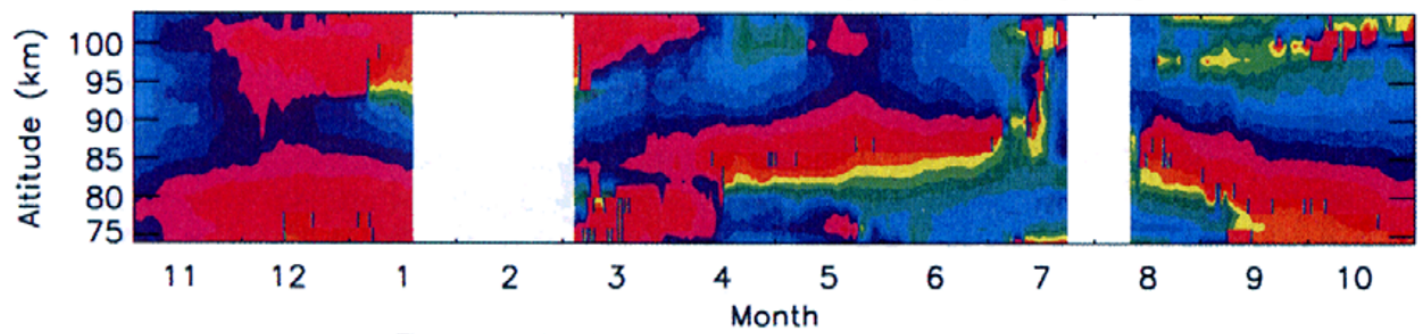

From 1996- 11- 1 To 1997- 10- 31
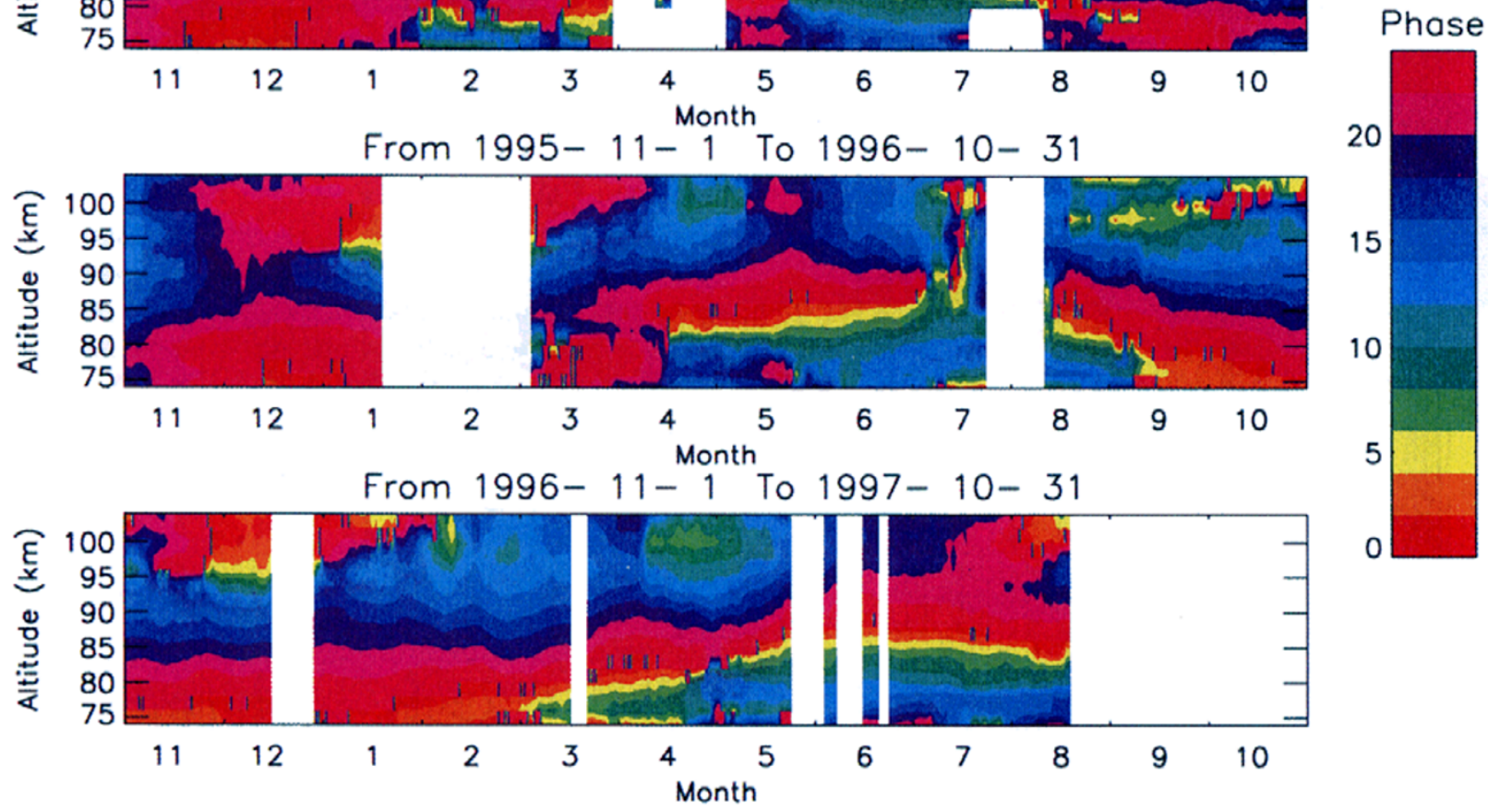

Fig. 3. The same as Fig. 1 except for the maximum phases for the northward tidal wind.

wind component for diurnal tides. In most months the phase value became earlier local time as the altitude increases, indicating the downward phase progression of tides. The phases rotated for approximately 24 hour in the entire height range with a thickness of $30 \mathrm{~km}$. However, the phase values became invariant above about $85 \mathrm{~km}$ in June-July in 1993, 1994 and 1997. Moreover, in January, 1993 and in December, 1994 and 1995 the phase did not vary largely along the altitude, but it was rather constant at around 18-22 LT, indicating that the diurnal tides became evanescent.

A fairly smooth seasonal variation in the meridional phase was persistently repeated for five years, which seems to correspond to that in the tidal amplitudes in Fig. 1, although considerable year-to-year variation was embedded as well. The seasonal march of the color tone in Fig. 3 can be approximated by a sinusoidal curve. For an example, the altitude 
corresponding to 20 LT located at about $85 \mathrm{~km}$ in MarchApril in 1993. It then started to ascend in May, reached 95 $\mathrm{km}$ in June-July, and descended to $85 \mathrm{~km}$ in October. Similar seasonal variation can be seen in other years, although some deviations are recognized in each year.

We show in Figs. 4(a) and (b) time variations of the tidal phases at 82, 88 and $94 \mathrm{~km}$ for the meridional and zonal components, respectively. The phase values determined every day by sliding the 31 day segment are plotted in Fig. 4 . Note that we did not apply a low pass filter in Fig. 4, since it may distort the phase variations particularly around datagaps. Although short-period fluctuations are sometimes recognized, an asymptotic smooth seasonal cycle can be identified.

At $82 \mathrm{~km}$ in Fig. 4(a) a clear annual cycle for the meridional phases was repeated for five years in 1993-1997. That is, the phases stayed around 18-22 LT from September to February, and rotated rapidly for 24 hours in March-August. Note that the phases rotated in the opposite direction in July-August in 1996, although the overall seasonal variations were similar to those in other years.

In Fig. 4(a) the phases at $88 \mathrm{~km}$ generally became ear-

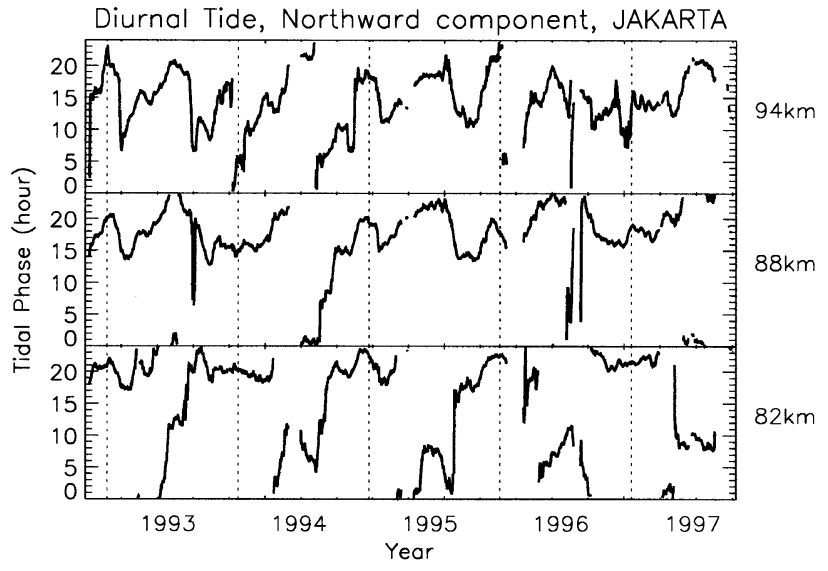

(a)

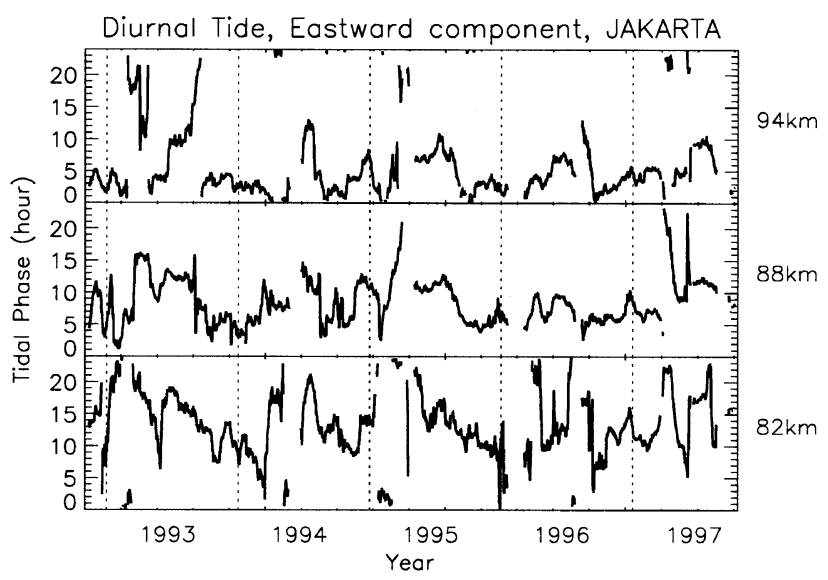

(b)

Fig. 4. The same as Fig. 2 except for the daily determinations of the maximum phases using a 31-day data segment for (a) the northward and (b) eastward components of diurnal tide. lier by about $4-5$ hours relative to those at $82 \mathrm{~km}$, and the variations were very consistent with those at $82 \mathrm{~km}$ from September to March. However, the phases at $88 \mathrm{~km}$ did not necessarily rotate for 24 hours in April-August, except in 1994. The phase values at $94 \mathrm{~km}$ became earlier again by about 4-5 hours to those at $88 \mathrm{~km}$, and their seasonal variations were very consistent throughout 1993-97. Note that the rapid phase change in May-July at $88 \mathrm{~km}$ was seen in 1994 and 1996, producing a biennial periodicity. The phases fluctuations in 1996 might be considered as statistical deviations due to data-gaps. However, as we describe in a later section, the phase profile in July 1996 was very consistent along altitude.

The zonal phases at $82 \mathrm{~km}$ in Fig. 4(b) repeated an annual cycle in 1993-95, then, rather irregular variations appeared after April 1996. The zonal phases at $88 \mathrm{~km}$ generally became earlier by about 5 hours, and their seasonal cycle in 1993-1995 was very similar to that at $82 \mathrm{~km}$, although the range of the variations became relatively smaller. Note that the variations in 1996-1997 were fairly consistent between 82 and $88 \mathrm{~km}$, particularly after October 1996. At $94 \mathrm{~km} \mathrm{a}$ persistent seasonal cycle of the zonal phases was seen, which was shifted by about 4 hours relative to the results at $88 \mathrm{~km}$.

\section{Comparison of Diurnal Tide between Three Radar Sites and GSWM}

This section is devoted to a correlative study on the seasonal variations of diurnal tide by using the three radar observations at Jakarta, Pontianak and Christmas Island as well as GSWM. We further investigate the detailed latitudinal structure of the diurnal tide near the equator.

According to a prediction by GSWM, diurnal tides in the MLT region are generally symmetrical relative to the equator at low latitudes. That is, the meridional phase is reversed across the equator, while, the zonal phase exhibits a gradual change along longitude. Further, amplitudes of the meridional wind velocity approaches zero near the equator, associated with a steep amplitude increase at low latitudes. Although the zonal amplitude is also small on the equator, its increase rate along the latitude is more gradual than for the meridional component.

For this study tidal parameters of GSWM are provided in four seasons on January 15, April 15, July 15 and October 15 at both northern and southern latitudes with a $3^{\circ}$ mesh interval, and every about $4 \mathrm{~km}$ along altitude.

We concentrate on a correlative analysis of the radar results from November 1995 to July 1997, when data from the Pontianak and Christmas Island MF radars are available. Hereafter, we abbreviate the radar sites as JKT, PNT and CHI for Jakarta, Pontianak and Christmas Island, respectively.

\subsection{Comparison of monthly mean tidal parameters at $90 \mathrm{~km}$}

We plot in Fig. 5 monthly mean values of the tidal amplitudes and phases for the three radar sites at $90 \mathrm{~km}$ where both the meteor echo rate for MWR and the data acquisition rate of $\mathrm{MF}$ radars are large, giving the highest accuracy. Note that we first analyzed tidal parameters every day using a 31-day segment, and averaged them in each month for 28 to $31 \mathrm{de}$ terminations, therefore, the total duration of the data records extends to about 60 days with a triangular weighting. The 


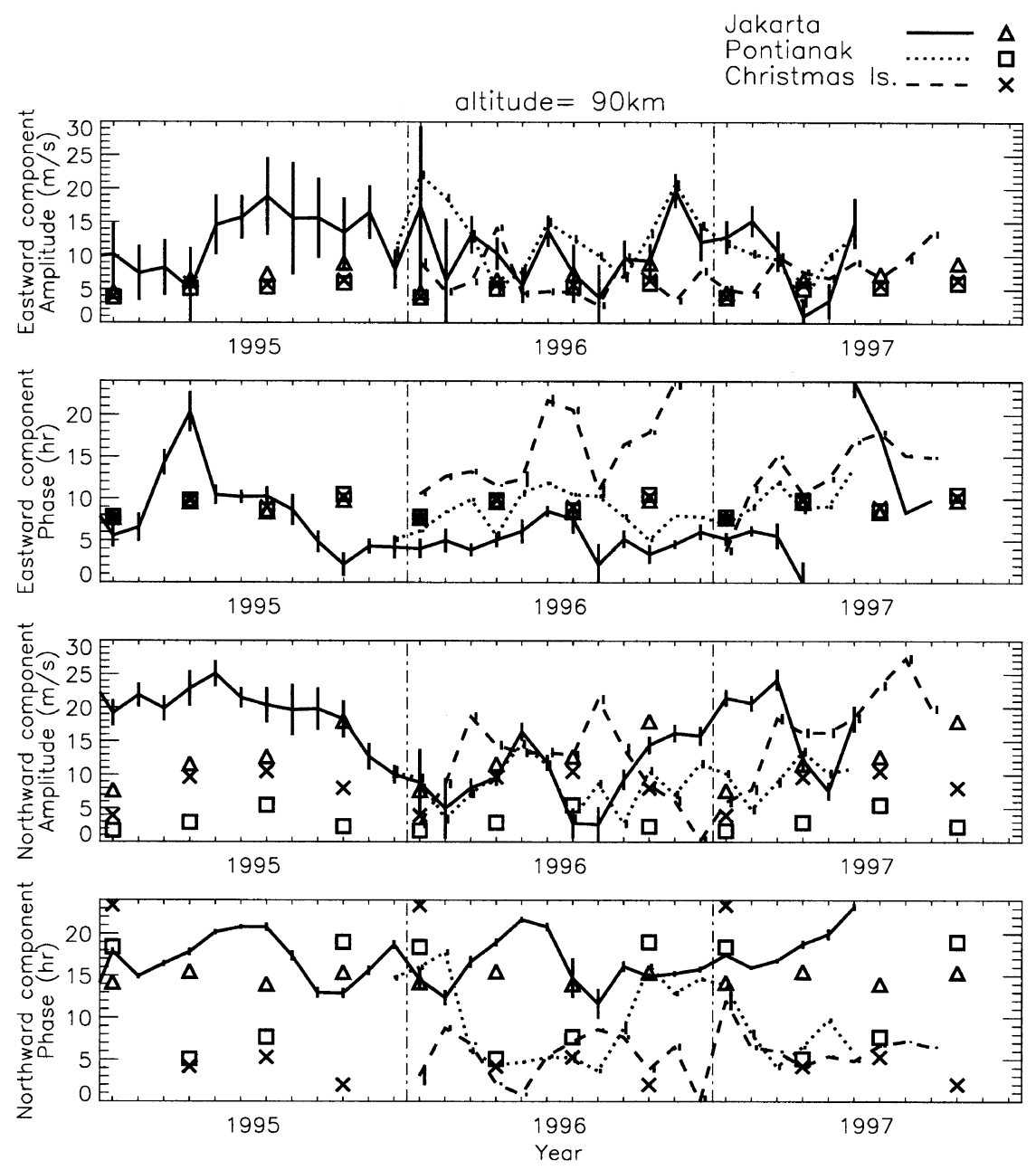

Fig. 5. Monthly determinations of the amplitudes and phases of diurnal tides at $90 \mathrm{~km}$ for the eastward and northward wind velocity. Solid, dotted and dashed lines correspond to the observations at Jakarta, Pontianak and Christmas Island, respectively. Triangle, square and cross symbols indicate the model results from GSWM at $6^{\circ} \mathrm{S}, 0^{\circ}$ and $3^{\circ} \mathrm{N}$, respectively.

results at JKT in Fig. 5 are essentially the same as plotted in Figs. 2 and 4. Error bars indicate the standard deviation of tidal parameters within one month. The GSWM values at $6^{\circ} \mathrm{S}, 0^{\circ}$ and $3^{\circ} \mathrm{N}$ are also plotted in the four months.

The zonal amplitudes at $\mathrm{CH}-\mathrm{I}$ ranged from 5 to $10 \mathrm{~m} / \mathrm{s}$ except in April, 1996, and agree reasonably well with GSWM at $3^{\circ} \mathrm{N}$. The zonal amplitudes at JKT and PNT were generally larger than those at CH-I. Although GSWM predicts nearly the same zonal amplitudes at these latitudes without significant seasonal variations, the observed results at JKT and PNT sometimes deviated greatly from the model values.

The meridional amplitudes in Fig. 5 were larger at CH-I than at JKT and PNT from February to September in 1996, when the amplitudes agreed very well between JKT and PNT. Then, the amplitudes at JKT became the largest among the three sites from October, 1996 to March, 1997, while those at PNT were not enhanced. GSWM agrees well with the meridional amplitudes at JKT from October 1995 to October 1996. Note, however, that the tidal amplitudes in this period at JKT seem to be considerably smaller than in other years, as shown in Fig. 1, therefore, the meridional amplitudes at JKT were generally larger than the GSWM prediction in other years, as recognized in Fig. 5 before July, 1995 and in January, 1997. Although the meridional amplitudes by GSWM are smaller than $5 \mathrm{~m} / \mathrm{s}$ on the equator throughout a year, the PNT results sometimes exceeded $10 \mathrm{~m} / \mathrm{s}$.

It is noteworthy that the seasonal variations of tidal amplitudes correlated well between JKT and PNT for both zonal and meridional components. In particular, the meridional amplitudes were almost identical from November, 1995 to July, 1996. On the other hand, the amplitude variations at $\mathrm{CH}-\mathrm{I}$ mostly disagreed with the results at JKT and PNT, in particular, an anti-correlation can be recognized for the meridional component. That is, the meridional amplitudes at CH-I were enhanced in July-September, 1996 when the JKT and PNT values became minimum. On the other hand, the CH-I values were depressed from November, 1996 to February, 1997, while large values were seen at JKT.

According to GSWM, the zonal phases are predicted to stay at 8-10 LT near the equator, which agrees fairly well with the results at PNT in Fig. 5. However, the phases at CHI largely deviated from GSWM in July and October, 1996. Seasonal variations of the zonal phases correlated reasonably well between PNT and JKT in 1996. But, the phases at JKT 
Eastward component (Diurnal)
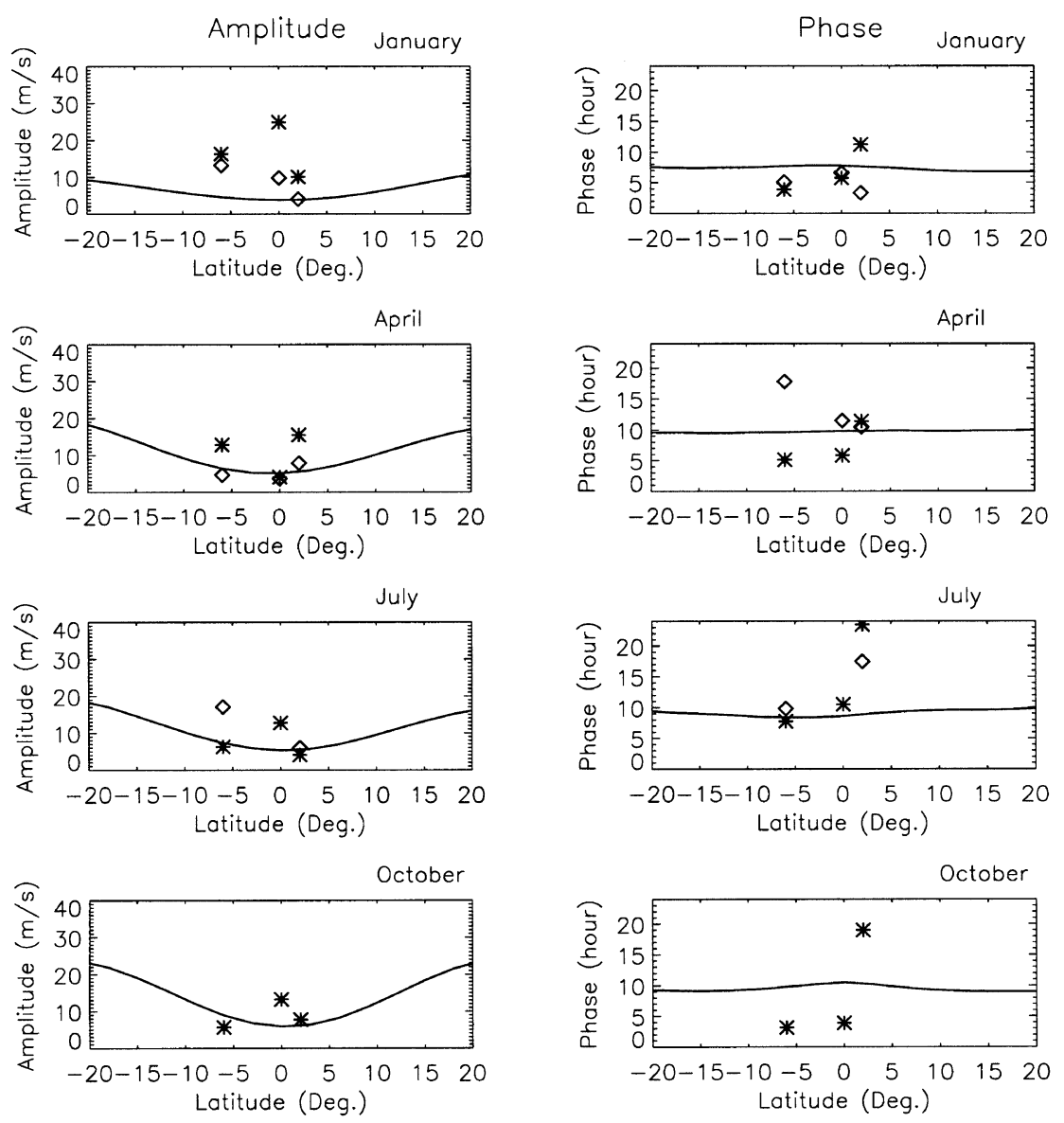

Fig. 6. Latitudinal sections of amplitudes (left) and phases (right) of diurnal tides at $90 \mathrm{~km}$ for (a) the eastward and (b) the northward wind velocity at Jakarta $\left(6^{\circ} \mathrm{S}\right)$, Pontianak $\left(0^{\circ}\right)$ and Christmas Island $\left(2^{\circ} \mathrm{N}\right)$. Four panels (from top to bottom) correspond to the determinations in January, April, July and October, and asterisks and squares indicate observations in 1996 and 1997, respectively.

were generally earlier than those at PNT by 3-6 hours except in April.

It is clear that the meridional phases at JKT repeated a persistent annual variation in 1995-1996. That is, they ranged 13-16 LT in January-February, gradually increased to 2021 LT in March-June, they then decrease to 13-14 LT by September-October.

Vincent et al. (1988) compared the seasonal variations of the tidal phases between Kyoto $\left(35^{\circ} \mathrm{N}\right)$ and Adelaide $\left(35^{\circ} \mathrm{S}\right)$. The meridional phases at Kyoto in their figure 2 show a clear annual variation, which differ from the phase values at JKT in Fig. 5 by almost 12 hours. That is, the seasonal variations are nearly phase-reversed between Kyoto and JKT, being consistent with the GSWM prediction. However, the phases at JKT did not necessarily agree with those at Adelaide, also plotted in figure 2 by Vincent et al. (1988).

The meridional phases at PNT agreed well with the CH-I results from March to September in 1996 and 1997, while they became close to the JKT values from October to February. A transition between the two states occurred in equinoxes.

\subsection{Latitudinal variation}

We plotted in Fig. 6 latitudinal distribution of the tidal amplitudes and phases at $90 \mathrm{~km}$ in the six observation periods, together with the GSWM results in each month. Since GSWM provides tidal parameters every $3^{\circ}$ along latitude, we linearly interpolated a vector, that shows the tidal amplitude and maximum phase, every $0.06^{\circ}$. Because tidal amplitudes become small near the equator for both zonal and meridional winds, determination of the observed phases could involve a significant uncertainty. As a matter of fact, reliable range of the monthly phase values became $0.5-2$ hours when the corresponding amplitudes were smaller than about $5 \mathrm{~m} / \mathrm{s}$. However, the error was much less for larger tidal amplitudes.

The latitude variation of the zonal amplitudes in Fig. 6(a) agreed best with GSWM in April, 1997. Although the good agreement was again seen at PNT in April 1997, the amplitudes at JKT and CH-I exceeded GSWM in 1997. In other months in 1996, however, the zonal amplitudes showed a peak at the equator, considerably deviating from GSWM. On the other hand, GSWM agrees well at JKT and CH-I in July and October, 1996.

The observed zonal phases in Fig. 6(a) exhibited signifi- 
Northward component (Diurnal)
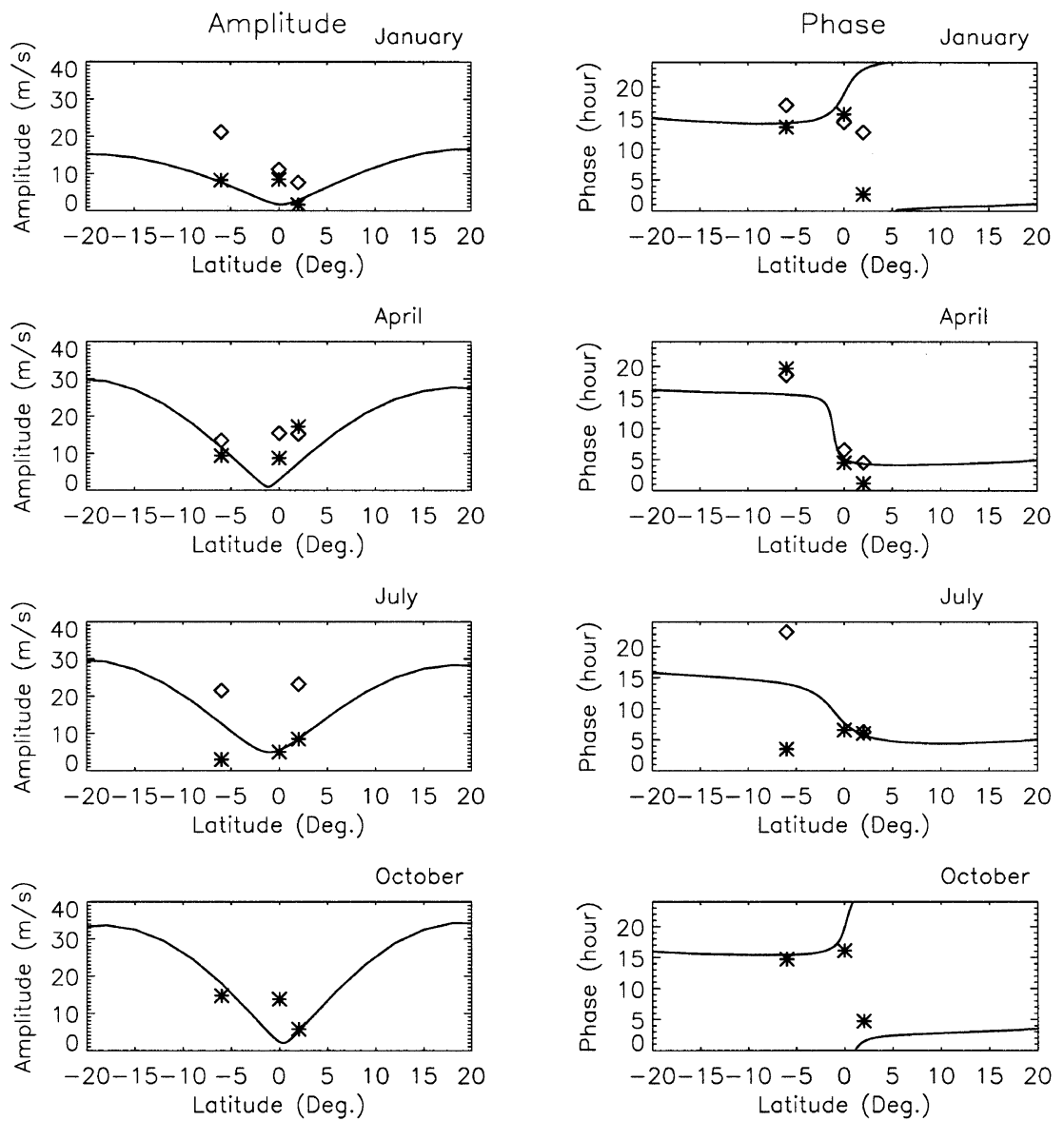

Fig. 6. (continued).

cant variations along latitude and season, although GSWM predicts only small changes. As a result, GSWM shows a reasonable agreement in January, while it does not describe at all the radar results in October. Note that the zonal phase values were nearly the same between JKT and PNT, except in April 1997. While those at CH-I retarded by about 5 hours relative to the PNT phases in January and April, and became almost phase-reversed in July and October, 1996. Therefore, the tidal structure could vary considerably across the equator, or, it may not be zonally symmetric, so, the rapid changes between PNT and CH-I occurred due to the large longitudinal separation between these radar sites.

In Fig. 6(b) GSWM predicts a minimum of the meridional wind near the equator. The observed meridional amplitudes in 1996 showed reasonable agreement with the GSWM, especially for the JKT and CH-I values, although discrepancy can be seen in April and July for JKT and CH-I, respectively. However, the PNT values were generally larger than GSWM, except in July, 1996 when GSWM agrees well with the observation. In 1997, the meridional amplitudes were generally larger than the previous year as discussed earlier.

The meridional phases at PNT were nearly the same as the JKT value in January, 1996 and October, 1996. Then, a stepwise shift of the meridional phase was detected within a small latitude range between $\mathrm{PNT}\left(0^{\circ}\right)$ and $\mathrm{CH}-\mathrm{I}\left(2^{\circ} \mathrm{N}\right)$. Note that the CH-I phases in January differed largely between 1996 and 1997, such that the phase jump disappeared in 1997. On the other hand, the PNT phases were close to the CH-I values in April in 1996 and 1997, and July 1996, therefore, the phase reversal seemed to be located between PNT $\left(0^{\circ}\right)$ and JKT $\left(6^{\circ} \mathrm{S}\right)$. GSWM generally describes well the latitude variations of the meridional phases near the equator, except for the JKT values in July.

\subsection{Inter-comparison of tidal profiles}

We now study an inter-comparison on the height structure of diurnal tides between the radar observations as well as GSWM. We show in Fig. 7 profiles of amplitudes and phases of diurnal tide at JKT, PNT and CH-I using a 31-day data segment centered on the respective model date; that is, January 16, April 16, July 16, October 16 in 1996, January 16 and April 16, 1997. The GSWM results at $6^{\circ} \mathrm{S}, 0^{\circ}$ and $3^{\circ} \mathrm{N}$ are also illustrated at four altitudes.

The zonal amplitudes ranged from about 5 to $15 \mathrm{~m} / \mathrm{s}$, except for the PNT results in January, 1996, when the amplitudes became as large as $20-30 \mathrm{~m} / \mathrm{s}$. The meridional amplitudes were generally larger than the zonal component by $5-10 \mathrm{~m} / \mathrm{s}$, and a large enhancement was seen at JKT in January, 1997. 

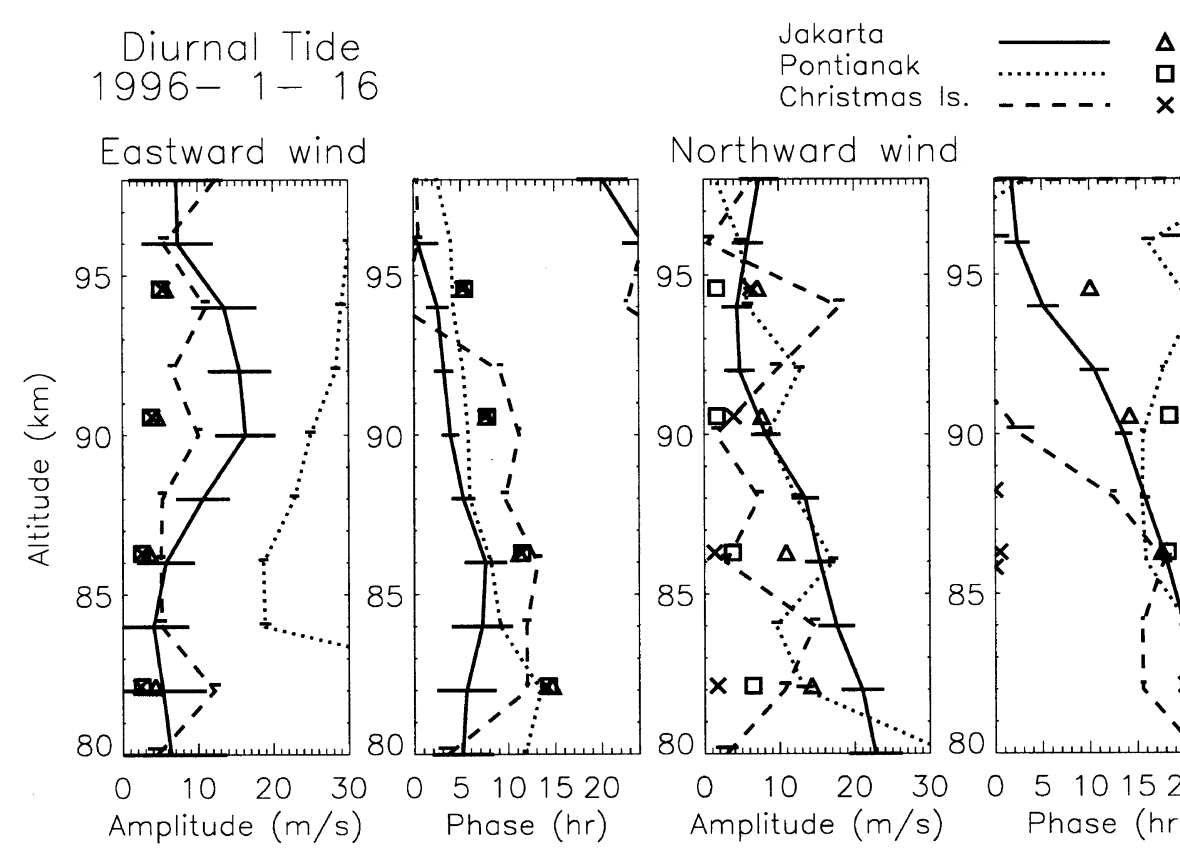

Northward wind

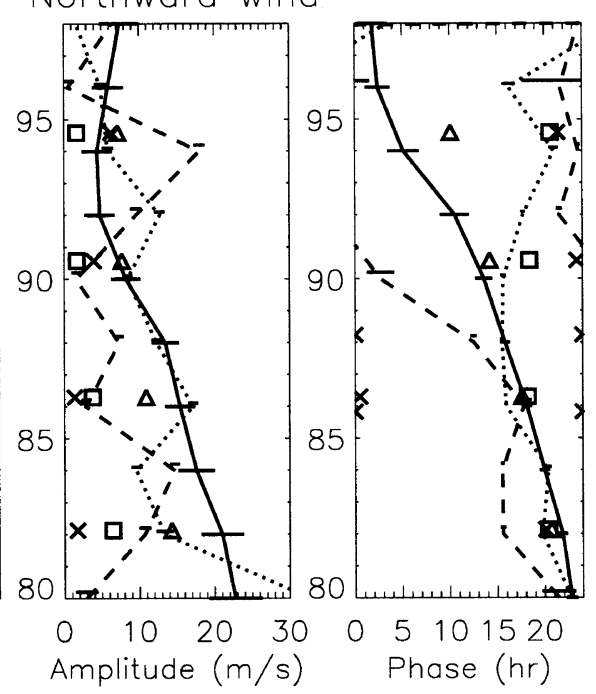

(a)
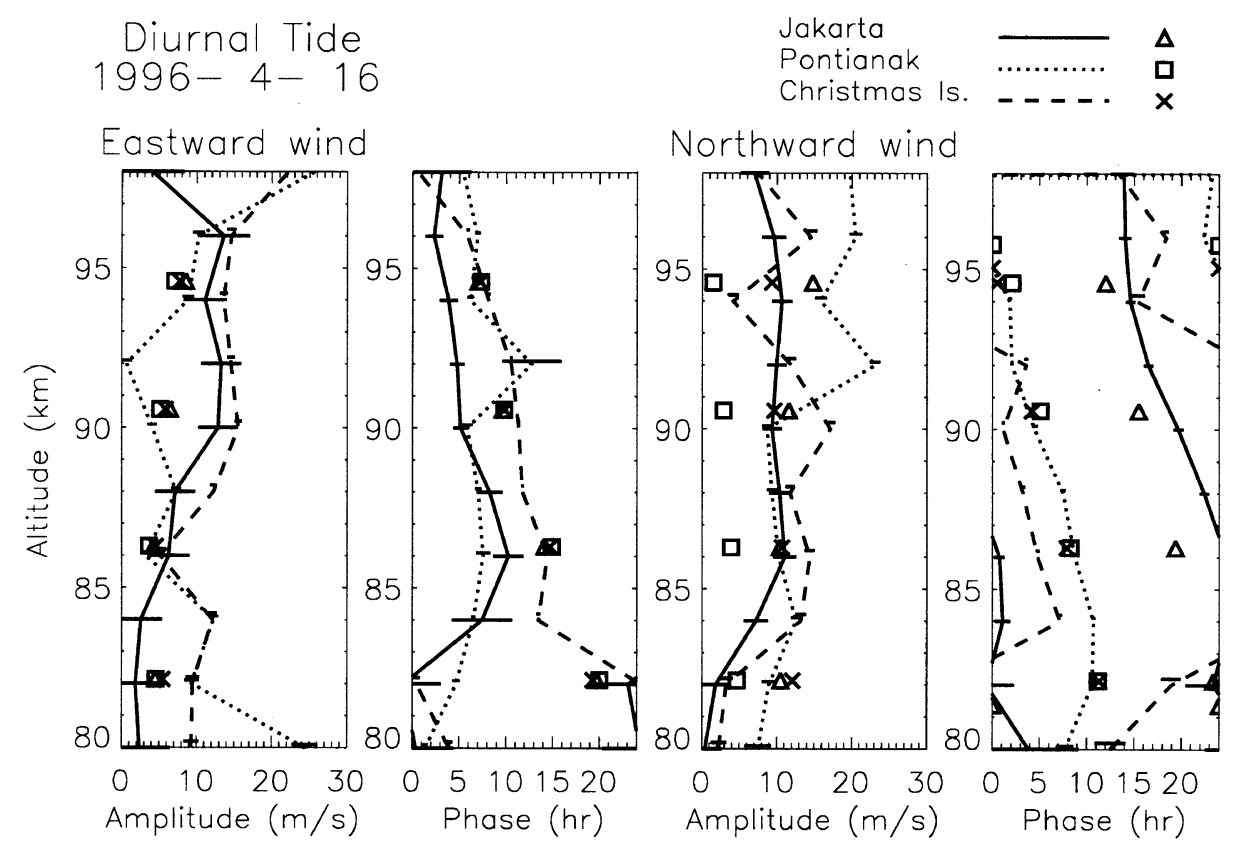

(b)

Fig. 7. Amplitudes and maximum phases in local time of diurnal oscillations for the eastward (left) and northward (right) wind velocity. Panel (a) shows the results on January 16, 1996 using a 31-day data segment at Jakarta (solid line), Pontianak (dotted line) and Christmas Island (dashed line). Triangle, square and cross symbols indicate the model results from GSWM at $6^{\circ} \mathrm{S}, 0^{\circ}$ and $3^{\circ} \mathrm{N}$, respectively. Panels (b)-(f) correspond to the profiles on April 16 , 1996, July 16, 1996, October 16, 1996, January 16, 1997 and April 16, 1997, respectively.

The results in January plotted in Figs. 7(a) and (e) indicate that overall structure of the zonal phase, including the progression rate with altitude, was consistent among the three radar results as well as GSWM. Profiles of the meridional phases in Fig. 7(a) were similar between JKT and PNT below $90 \mathrm{~km}$, and the latter retarded above $90 \mathrm{~km}$, which is explained well by GSWM. Similar phase structures were also seen in the next year shown in Fig. 7(e). Phases at CH-I sometimes deviated largely probably due to the small tidal amplitudes.

The observed tidal amplitudes in January were generally larger than GSWM. Moreover, year-to-year variations in the tidal amplitudes were recognized between Figs. 7(a) and (e). For example, the zonal amplitudes at PNT were largely enhanced in January 1996, but, the corresponding phase structure did not differ greatly from the profile in 1997, showing a 

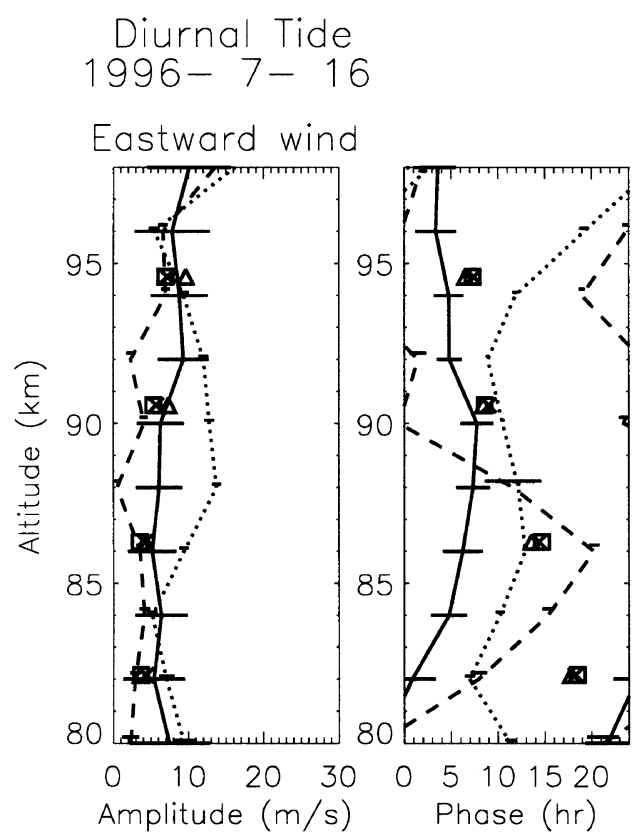

Northward wind
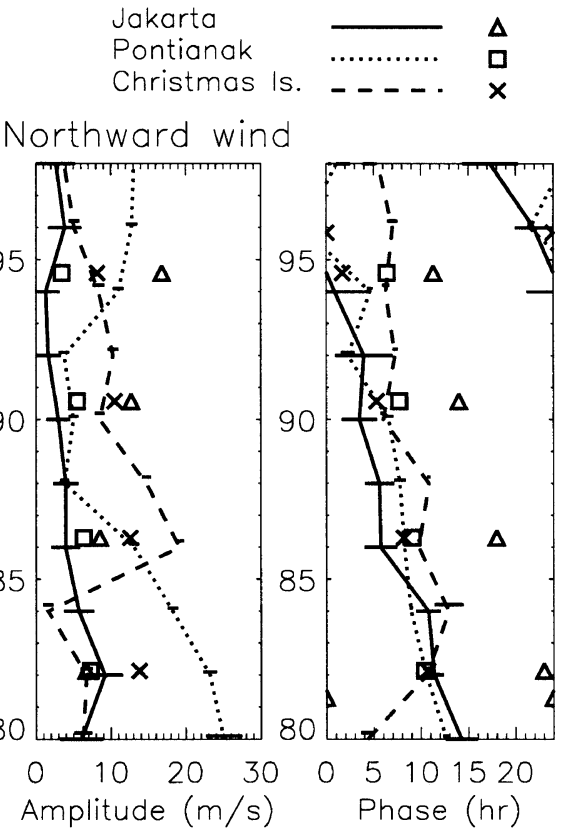

(c)

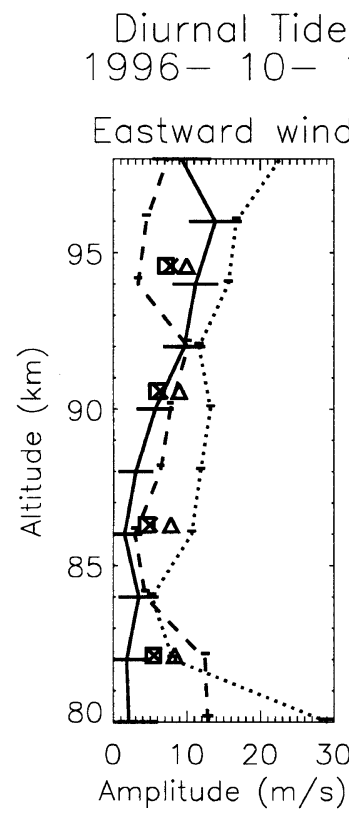

16

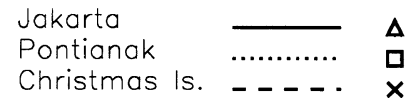

Northward wind
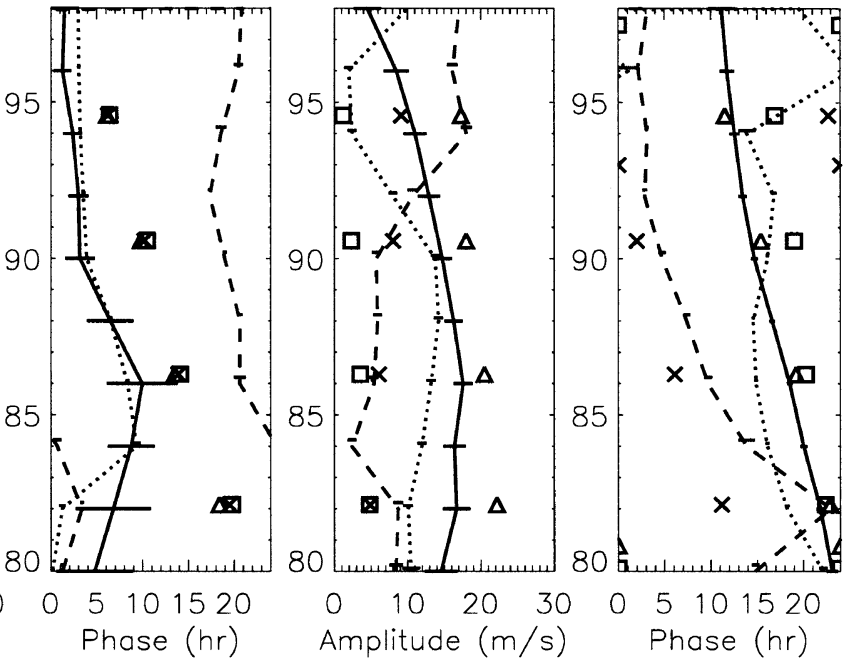

(d)

Fig. 7. (continued).

good agreement with GSWM. Note also that the meridional amplitudes at JKT became larger in 1997 than in 1996. However, the phase structure again unchanged below about $90 \mathrm{~km}$. Therefore, it can be suggested that year-to-year variations of diurnal tides seem to mostly appear in their amplitudes, but the phase structure is rather invariant.

The observed profiles in April, 1997 shown in Fig. 7(f) agreed very well with GSWM, except for the zonal phase at JKT above $90 \mathrm{~km}$ and the meridional amplitudes at PNT. A reasonable agreement was also recognized in the previous year plotted in Fig. 7(b), in particular, the meridional com- ponent at JKT was consistent with GSWM in both 1996 and 1997. The meridional phases at PNT was described well by GSWM, although the observed meridional amplitudes at PNT were much greater than GSWM.

For Fig. 7(c) there exists only partial agreement between the observed profiles and GSWM. That is, the observed zonal amplitudes at the three radar sites ranged near the model values, and the meridional phases at PNT and CH-I were consistent with GSWM. However, the zonal phases were rather irregular, and the meridional amplitudes at PNT and CH-I show a complicated structure. 

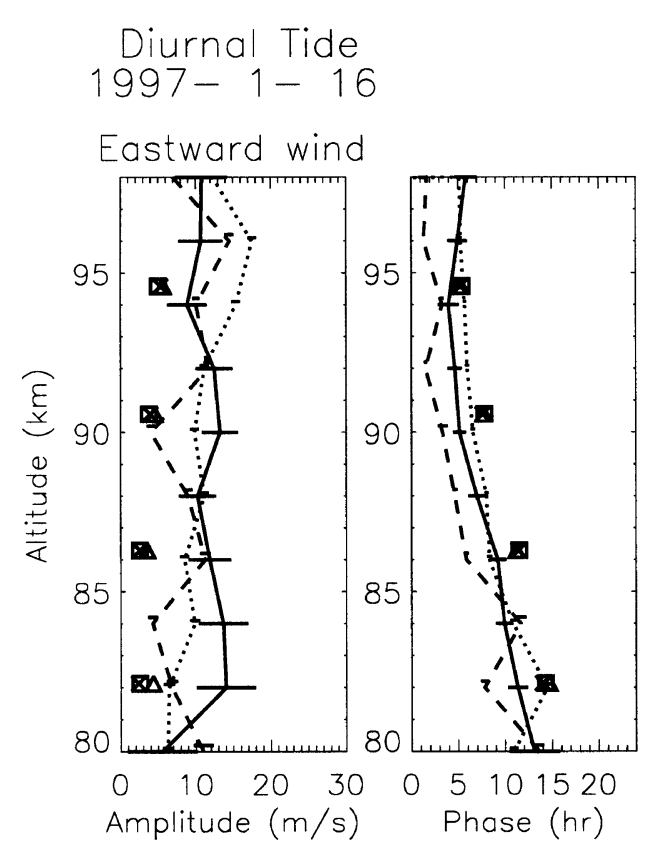

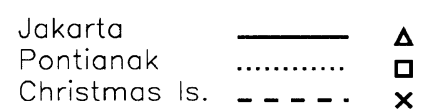

Northward wind

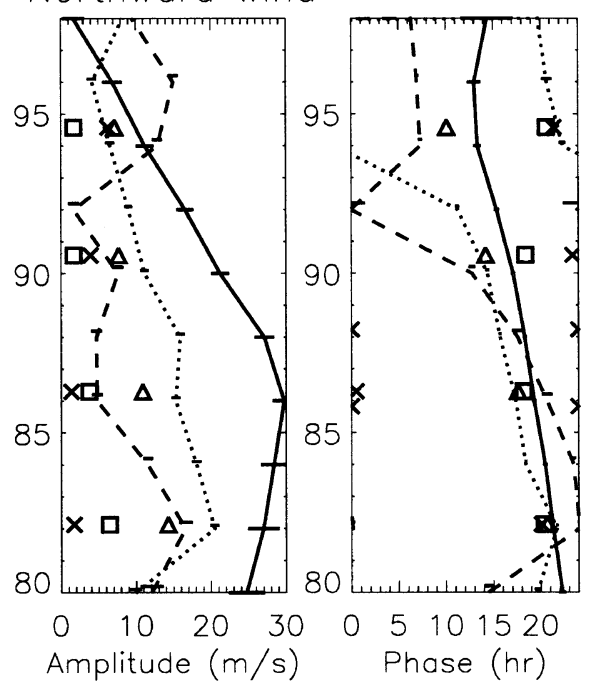

(e)

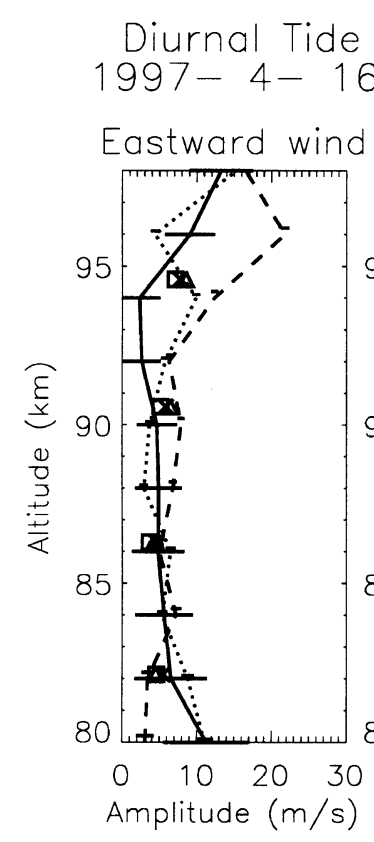

Diurnal Tide

$1997-4-16$

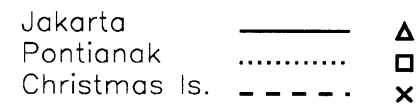

Northward wind

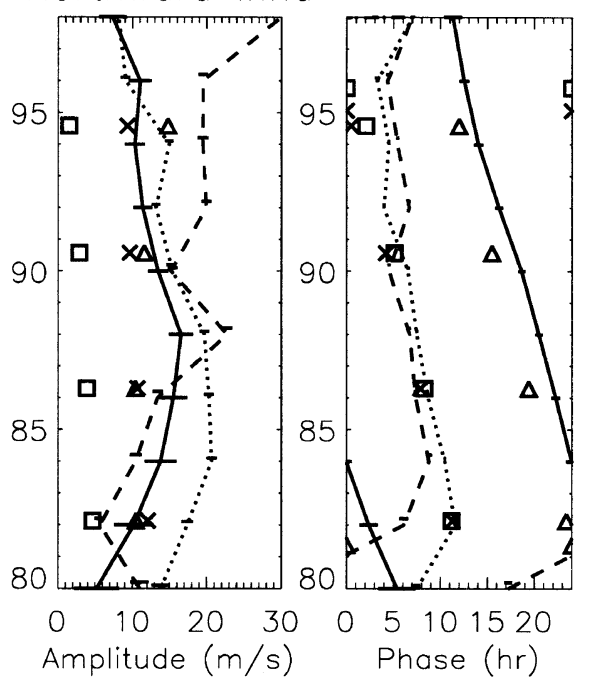

(f)

Fig. 7. (continued).

Moreover, the meridional phases at JKT were shifted by 10-13 hours from GSWM, although the phase progression was similar to the model. Figure 4(a) suggests that a rapid phase variation occurred around July, 1996, which might be caused by an error in the analysis due to data gaps, or a noise contaminated from geophysical phenomena other than tides. However, Fig. 7(c) indicates that the phases were coherent in the entire observation height range, which can be considered as the tidal behavior, although it could be a peculiar event. Therefore, the biennial periodicity of the meridional phases at $88 \mathrm{~km}$ in Fig. 4(a) does not seem to be an apparent phe- nomena. Considering the long-term variations of the tidal amplitudes at $88 \mathrm{~km}$ in Fig. 2 as well, there seems to exist biennial variations of diurnal tides in the equatorial MLT region.

Note that the monthly mean value for the meridional phase at $90 \mathrm{~km}$ in July, 1996 was estimated as about $15 \mathrm{LT}$ in Fig. 5, showing a good agreement with the GSWM prediction (14 LT), while the JKT result at $90 \mathrm{~km}$ in Fig. 7(c) was 3.5 hours. This discrepancy is attributed to the difference in the duration of the analyzed data, that is, the rapid phase changes were smoothed out in Fig. 5. 
In Fig. 7(d) the observed zonal amplitudes were fairly close each other, being consistent with GSWM. Moreover, the meridional amplitudes at JKT and $\mathrm{CH}-\mathrm{I}$ agreed fairly well with GSWM, while the PNT values were much greater than the model. The meridional phases at JKT agreed well with GSWM, and those at PNT and CH-I showed a reasonable agreement. However, the zonal phases exhibit significant disagreement from GSWM. That is, the zonal phase values at JKT and PNT proceeded GSWM by 5-7 hours, although their phase progression rate was similar to the model. The $\mathrm{CH}-\mathrm{I}$ results retarded from GSWM, and were nearly phasereversed above $86 \mathrm{~km}$ relative to the JKT and PNT results.

It is rather difficult to clearly judge the similarity of the amplitudes profiles, consisting of a complicated structure. Therefore, we summarize here comparison of the tidal behavior between the three sites on the basis of their phase structures.

The height profiles of the zonal phases were very consistent between JKT and PNT in January (Figs. 7(a) and (e)) and October (Fig. 7(d)), and they agreed between 84 and 88-90 $\mathrm{km}$ in April (Figs. 7(b) and (f)). But, the zonal phases in July were rather irregular.

The meridional phases agreed fairly well between the three sites in January (Figs. 7(a) and (e)), though perturbations are seen in the CH-I profiles. Then, in April (Figs. 7(b) and (f)) the phases at PNT and CH-I were shifted by nearly 12 hours, while they did not change significantly at JKT. In October (Fig. 7(d)) the PNT phases jumped again by about 12 hours, approaching to the values at JKT. Although the JKT phases became similar to CH-I and PNT values in July (Fig. 7(c)), it could be a peculiar phenomenon in 1996, since the JKT phases at $90 \mathrm{~km}$ deviated from the climatological behavior shown in Figs. 4(a) and 5. The GSWM prediction mostly agrees well at the three radar sites, except for the meridional phases in July, 1996 at JKT.

\section{Concluding Remarks}

MWR observations in Jakarta, Indonesia from November 1992 to August 1997 has been used to determine a climatology of diurnal tide in the equatorial MLT region. A correlative study between the Jakarta (JKT) MWR and MF radars in Pontianak (PNT) and Christmas Island (CH-I) have been conducted in order to detect latitudinal variations of the diurnal tide. The behavior of the diurnal tides is compared with the GSWM.

The zonal phases show an overall consistency between JKT and PNT, which is explained by a small phase variation along latitude near the equator. Seasonal variation of the meridional phases differ by 12 hours between JKT and Kyoto, consistent with the behavior of a global diurnal tide which is symmetrical relative to the equator. The meridional phase values at PNT, located on the equator, agree with those at CH-I and JKT in March-September and OctoberFebruary, respectively. It is suggested that "the equator for the diurnal tide" stays between $6^{\circ} \mathrm{S}(\mathrm{JKT})$ and the equator (PNT) from March to August, but it moves northward, and locates between $2^{\circ} \mathrm{N}(\mathrm{CH}-\mathrm{I})$ and the equator (PNT) from October to February. A clear transition between these two states is seen at PNT in March and September.

Amplitudes of the meridional wind velocity for diurnal tide are generally larger than the zonal component. The height of maximum meridional amplitudes showed an annual variation, clearly repeated for five years at JKT. It is noteworthy, however, that the tidal amplitudes show considerable interannual variations. In particular, the amplitudes were fairly small in 1996, and they were comparable between zonal and meridional components in this particular year. In addition, a biennial periodicity of tidal parameters was recognized.

The seasonal variation of the amplitudes for diurnal tide agreed very well in 1996 between JKT and PNT, especially for the meridional winds. However, considerable difference was recognized between $\mathrm{CH}-\mathrm{I}$ and PNT, suggesting a longitudinal variation of the tidal fields, possibly due to the effects of non-migrating tides.

Observed tidal parameters are compared with the GSWM in four seasons. When the tidal amplitudes are not too small, the GSWM describes the climatological characteristics of the seasonal and latitudinal variations of the diurnal tide near the equator fairly well.

Acknowledgments. This study is conducted as a part of an international collaborative project on observations of equatorial atmosphere between RASC of Kyoto University, the University of Adelaide, LAPAN and BPPT. The meteor wind radar in Jakarta and the MF radar in Pontianak have been operated by BPPT and LAPAN, respectively. We wish to thank Dr. M. E. Hagan for providing the tabulations of a numerical tidal model. We are particularly grateful to Dr. D. M. Riggin for helpful comments and careful reading of the manuscript. The Australian Research Council supports the research with the MF radars at Adelaide and Pontianak. The joint study in Indonesia is partly supported by Monbusho, Japan under grants 07044082 and 09044080 . The MF radar experiment in Pontianak is also supported by The Mitsubishi Foundation.

\section{References}

Burrage, M. D., M. E. Hagan, W. R. Skinner, D. L. Wu, and P. B. Hays, Long-term variability in the solar diurnal tide observed by HRDI and simulated by the GSWM, Geophys. Res. Lett., 22, 2641-2644, 1995a.

Burrage, M. D., D. L. Wu, W. R. Skinner, D. A. Ortland, and P. B. Hays, Latitudinal and seasonal dependence of the semidiurnal tide observed by the high resolution Doppler imager, J. Geophys. Res., 100, 11313-11321, 1995b.

Ekanayake, E. M. P., T. Aso, and S. Miyahara, Background wind effect on propagation of nonmigrating diurnal tides in the middle atmosphere, $J$. Atmos. Terr. Phys., 59, 401-429, 1997.

Forbes, J. M., Atmospheric tides 1, Model description and results for the solar diurnal component, J. Geophys. Res., 87, 5222-5240, 1982.

Forbes, J. M. and M. E. Hagan, Diurnal propagating tide in the presence of mean winds and dissipation: a numerical investigation, Planet. Space Sci., 36, 579-590, 1988.

Fritts, D. C. and J. R. Isler, First observations of mesospheric dynamics with a partial reflection radar in Hawaii $\left(22^{\circ} \mathrm{N}, 160^{\circ} \mathrm{W}\right)$, Geophys. Res. Lett. 19, 409-412, 1992.

Hagan, M. E., J. M. Forbes, and F. Vial, On modeling migrating solar tides, Geophys. Res. Lett., 22, 893-896, 1995.

Hsu, H. H. and B. J. Hoskins, Tidal fluctuations as seen in ECMWF data, Q. J. R. Meteorol. Soc., 115, 247-264, 1989.

Kato, S., Dynamics of the Upper Atmosphere, 233 pp., D. Reidel, Norwell, Mass., 1980.

Lieberman, R. S., Long-term variations of zonal mean winds and $(1,1)$ driving in the equatorial lower thermosphere, J. Atmos. Terr. Phys., 59, 1483-1490, 1997.

Manson, A. H., C. E. Meek, H. Teitelbaum, F. Vial, R. Schminder, D. Kürschner, M. J. Smith, G. J. Fraser, and R. R. Clark, Climatologies of semi-diurnal and diurnal tides in the middle atmosphere $(70-110 \mathrm{~km})$ at middle latitudes (40-55 $)$, J. Atmos. Terr. Phys., 51, 579-593, 1989.

Miyahara, S., Y. Yoshida, and Y. Miyoshi, Dynamic coupling between the lower and upper atmosphere by tides and gravity waves, J. Atmos. Terr. Phys., 55, 1039-1053, 1993. 
Nakamura, T., D. C. Fritts, J. R. Isler, T. Tsuda, R. A. Vincent, and I. M. Reid, Short-period fluctuations of the diurnal tides observed with lo-latitude MF and meteor radars during CADRE: Evidence for gravity wave/tidal interactions, J. Geophys. Res., 102, 26225-26238, 1997.

Tokioka, T. and I. Yagai, Atmospheric tides appearing in a global atmospheric general circulation model, J. Meteor. Soc. Japan, 65, 423-437, 1987.

Tsuda, T. and S. Kato, Diurnal non-migrating tides excited by a differential heating due to land-sea distribution, J. Meteor. Soc. Japan, 67, 43-55, 1989.

Tsuda, T., S. Kato, A. H. Manson, and C. E. Meek, Characteristics of semidiurnal tides observed by the Kyoto meteor radar and Saskatoon medium-frequency radar, J. Geophys. Res., 93, 7027-7036, 1988.

Tsuda, T., S. Fukao, M. Yamamoto, T. Nakamura, M. D. Yamanaka, T. Adachi, H. Hashiguchi, N. Fujioka, M. Tsutsumi, S. Kato, S. W. B. Harijono, T. Sribimawati, B. P. Sitorus, R. B. Yahya, M. Karmini, F. Renggono, B. L. Parapat, W. Djojonegoro, P. Mardio, N. Adikusumah, H. T. Endi, and H. Wiryosumarto, A Preliminary Report on Observations of Equatorial Atmosphere Dynamics in Indonesia with Radars and Radiosondes, J. Meteor. Soc. Japan, 73, 393-406, 1995.

Tsuda, T., T. Nakamura, A. Shimizu, and T. Yoshino, Observations of diurnal oscillations with a meteor wind radar and radiosondes in Indonesia, $J$. Geophys. Res., 102, 26217-26224, 1997.

Vial, F., Numerical simulations of atmospheric tides for solstice conditions, J. Geophys. Res., 91, 8955-8969, 1986.

Vincent, R. A. and D. Lesicar, Dynamics of the equatorial atmosphere: first results with a new generation partial reflection radar, Geophys. Res. Lett., 18, 825-828, 1991.

Vincent, R. A., T. Tsuda, and S. Kato, A comparative study of mesospheric solar tides observed at Adelaide and Kyoto, J. Geophys. Res., 93, 699$708,1988$.

Vincent, R. A., S. Kovalam, D. C. Fritts, and J. R. Isler, Long-term MF radar observations of solar tides in the low-latitude mesosphere: Interannual variability and comparisons with GSWM, J. Geophys. Res., 103, 86678683, 1998.

Williams, C. R. and S. K. Avery, Non-migrating diurnal tides forced by deep convective clouds, J. Geophys. Res., 101, 4079-4091, 1996.

T. Tsuda (e-mail: tsuda@kurasc.kyoto-u.ac.jp), K. Ohnishi, F. Isoda, T. Nakamura, R. A. Vincent, I. M. Reid, S. W. B. Harijono, T. Sribimawati, A Nuryanto, and H. Wiryosumarto 